Federal Reserve Bank of Minneapolis

Research Department Staff Report 314

November 2002

\title{
Wealth Inequality and Intergenerational Links
}

\author{
Mariacristina De Nardi* \\ University of Minnesota \\ and Federal Reserve Bank of Minneapolis
}

\begin{abstract}
Previous work has had difficulty generating household saving behavior that makes the distribution of wealth much more concentrated than that of labor earnings, and that makes the richest households hold onto large amounts of wealth, even during very old age. I construct a quantitative, general equilibrium, overlapping-generations model in which parents and children are linked by accidental and voluntary bequests and by earnings ability. I show that voluntary bequests can explain the emergence of large estates, while accidental bequests alone cannot, and that adding earnings persistence within families increases wealth concentration even more. I also show that the introduction of a bequest motive generates lifetime savings profiles more consistent with the data.
\end{abstract}

*I am grateful to Joe Altonji, Orazio Attanasio, Lisa Barrow, Marco Bassetto, Gary S. Becker, Marco Cagetti, Lars P. Hansen, Tim Kehoe, José A. Scheinkman, Jenni Schoppers, Ernesto Villanueva, Guglielmo Weber, three anonymous referees, and especially Thomas J. Sargent for helpful comments and suggestions. I thank the participants at seminars at many institutions for comments, and Martin Flodén, Paul Klein and David Domeij for discussions about the Swedish data. All errors are my own. All views expressed herein are those of the author and not necessarily those of the Federal Reserve Bank of Minneapolis or the Federal Reserve System. 


\section{Introduction}

The goal of this paper is to study the forces behind households' saving behavior that make the distribution of wealth much more concentrated than that of labor earnings and that push the richest households to hold onto large amounts of assets even during very old age.

Several papers have documented the fact that the distribution of wealth is much more concentrated than that of labor earnings and that it is characterized by a tiny fraction of households owning huge estates. (See, for example Hurst, Luoh, and Stafford (1998), Wolff (1987), Lillard and Willis (1978), Davies and Shorrocks (2000), Díaz-Giménez, Quadrini, and Ríos-Rull (1997).)

Among many possible reasons for wealth being much more concentrated than labor earnings is that, not only are different households at different positions in their life cycle (Huggett (1996)), but they also receive unequal intergenerational transfers (Hurd and Smith (1999)). The aggregate figures for such transfers are large (Kotlikoff and Summers (1981), Gale and Scholz (1994)). Transmission of human capital could also generate the emergence of very large estates (Mulligan (1997)).

Many have studied the saving decisions of the elderly. Among these, Dynan, Skinner, and Zeldes (1996) and Lillard and Karoly (1997) show that households with higher levels of lifetime income have higher saving rates, keep substantial amounts of assets (even during old age), and leave very large bequests. Carroll (1998) shows that neither standard life-cycle nor dynastic models can recover the saving behavior of rich and poor families at the same time.

I focus on the life cycle and the transmission of physical capital and earnings ability across generations and show that these forces can induce saving behavior that generates a distribution of wealth that is much more concentrated than that of labor earnings and that also makes the rich keep large amounts of assets in old age in order to leave bequests to descendants.

I adopt a computable, general equilibrium, incomplete-markets, life-cycle model in which parents and their children are linked by bequests, both voluntary and accidental, and by the transmission of earnings ability. Here the households save to self-insure against labor earnings shocks and life-span risk, for retirement, and possibly to leave bequests to their children. I calibrate the model to match relevant features of the data and study its 
implications for wealth concentration and saving behavior.

I find that voluntary bequests can explain the emergence of large estates, which are often accumulated in more than one generation, and characterize the upper tail of the wealth distribution in the data. Accidental bequests alone, even if unequally distributed, do not generate more wealth concentration.

The presence of a bequest motive also generates lifetime saving profiles more consistent with the data: saving for precautionary purposes and saving for retirement are the primary factors for wealth accumulation at the lower tail of the distribution, while saving to leave bequests significantly affects the shape of the upper tail.

Modeling bequests as a luxury good is key in matching both of these facts. The bequest motive to save is thus stronger for the richest households, who, even when very old, keep some assets to leave to their children. The rich leave more wealth to their offspring, who, in turn, tend to do the same. This behavior generates some large estates that are transmitted across generations because of altruism, while being quantitatively consistent with the elasticity of the savings of the elderly to permanent income that has been estimated from microeconomic data (Altonji and Villanueva (2002)).

A human-capital link, through which children partially inherit the productivity of their parents, generates an even more concentrated wealth distribution. More productive parents accumulate larger estates and leave larger bequests to their children who, in turn, are more productive than average in the workplace.

As a further test of the model, I also calibrate it to Swedish data. The cross-country comparison between the United States and Sweden suggests that intergenerational links are also important in economies where redistribution programs are more prominent and there is less inequality. Even when I change only the smallest possible number of parameters to match key Swedish data, the model with both intergenerational links does a better job of reproducing wealth inequality in Sweden. This is particularly interesting because in Sweden the very richest hold a smaller amount of total wealth than in the United States, while the poorest hold even less wealth than in the United States. As a result, the Gini coefficient of Swedish wealth is close to that of the United States. As I argue later on, the behavior of the poorest is well explained in the model by a more generous social insurance network in Sweden, 
while the bequest motive is quantitatively important in explaining the wealth accumulation behavior of the richest even in Sweden.

\section{A. Contributions with respect to the literature}

The literature on inequality, bequests, and saving behavior is vast. Among the earlier partial equilibrium studies, Davies (1982) analyzes the effects of various factors, including bequests, on economic inequality in a one-period model without uncertainty. In his setup one generation of parents cares about their children's future consumption, and there is regression to the mean between parents' and children's earnings. As a consequence, the income elasticity of bequests is high and inherited wealth is a major cause of wealth inequality. Like Davies (1982), I adopt adopt a general equilibrium, overlapping-generations setup, with lifetime and earnings uncertainty, in which the expectation of receiving bequests from the parents influences their children's saving behavior. I also study the impact of various saving motives over the life cycle and their effects on accumulated wealth, and I model both accidental and voluntary bequests and their impact on wealth inequality.

Laitner (1992) adopts a partial equilibrium model with two-sided altruism among generations, constraints on net worth being nonnegative, and random lifetime earnings. He shows that intergenerational transfers are a luxury good in this setup and that liquidity constraints are less binding for generations receiving larger transfers. He also discusses how this economy can generate realistic capital-to-output ratios. He does not explore the implications of his model for wealth inequality, and he abstracts from lifetime uncertainty and earnings uncertainty over the life cycle.

Most of the general equilibrium, quantitative models of wealth inequality fall broadly into two categories. The first group of papers studies overlapping-generations economies where all savings arise over the life cycle, while the second group studies economies with infinitely lived dynasties.

In the first group of papers, Hubbard, Skinner, and Zeldes (1995) focus on the effects of social insurance programs on the wealth holdings of poor people. My paper, instead, concentrates on the effect of intergenerational links, especially on the upper tail of the wealth distribution. 
Gokhale et al. (1998) quantify the amount of intra-generational wealth inequality for the 66-year-old households arising from inheritances in a setup with random death and fertility, assortative mating, and heterogeneous human capital. Families are assumed to have a constant per capita consumption profile (which results in a large aggregate flow of accidental bequests) and do not take into account expected bequests when making consumption and saving decisions. In their model inheritances play an important role in generating intragenerational wealth inequality because social security annuitizes the savings of poor and middle-income people. In contrast with Gokhale et al. (1998), and consistent with the data, my model generates higher saving rates for people with higher lifetime income and age-savings profiles consistent with the empirical observations.

Huggett (1996) is interested in how much wealth inequality can be generated using a pure life-cycle model with earnings shocks and an uncertain life span. His model matches the U.S. Gini coefficient for wealth, but the concentration is obtained by having more people in the lower tail and a much thinner upper tail than observed in the actual wealth distribution. Compared to Huggett's (1996) model, I add voluntary bequests and intergenerational transmission of ability.

Heer (1999) adopts a life-cycle model in which rich and poor people have different tastes for leaving bequests. His characterization of the labor earnings process (people can be employed or unemployed) does not generate enough earnings inequality compared with the data, and his model does not produce a large wealth concentration. Compared to Heer's (1999) model, my model does not rely on heterogeneous preferences and adopts a richer earnings process, which matches earnings persistence (as measured in microeconomic data sets), and also generates a reasonable distribution of labor earnings in the population. By including an intergenerational transmission of earnings ability and comparing two very different countries, my paper also sheds light on the relative contribution of various factors in generating wealth concentration.

As for the second group of papers, Krusell and Smith (1997) study an economy populated by infinitely lived dynasties that face idiosyncratic income and preference shocks. They show that it is possible to find a stochastic process for the dynasties' discount factor to match the cross-sectional distribution of wealth. In contrast, I explicitly model the life-cycle struc- 
ture and intergenerational links, calibrate them to the data, and study the impact of each of these forces.

Castañeda, Díaz-Giménez, and Ríos-Rull (1998) study a model populated by dynastic households that have some life-cycle flavor: workers have a constant probability of retiring at each period, retirees face a constant probability of dying, and each generation cares about its own offspring. Quadrini (2000) constructs an infinitely lived agent model in which agents can choose to be entrepreneurs. The simplified structures of these dynastic models do not allow proper accounting for the life-cycle pattern of savings and the role of bequests in generating wealth inequality.

In between the first and second group of papers, recent work by Laitner (2001) mixes life-cycle and dynastic behavior: all households save for life-cycle purposes, but only some of them care about their own descendants. There are perfect annuity markets; therefore, all bequests are voluntary. There is no earnings risk over the life cycle; hence, no precautionary savings. The concentration in the upper tail of the wealth distribution is matched by choosing the fraction of households that behave as a dynasty and also depends on the assumptions on the distribution of wealth within the dynasty, which is indeterminate in the model.

My results are related to other studies that do not focus on the wealth distribution in particular, but on saving choices more generally. Carroll (1998) concentrates on the fact that in the data households with higher levels of lifetime income have higher lifetime saving rates. He shows that neither standard life-cycle nor dynastic models can recover the saving behavior of rich and poor families at the same time. To solve this puzzle he suggests a "capitalist spirit" model, in which finitely lived consumers have wealth in the utility function. This model can be calibrated to make wealth a luxury good, thus rendering nonhomothetic preferences. In my model, nonhomotheticity arises because parents care about leaving bequests to their children. This setup allows me to test whether the assumptions I make are consistent not only with the saving behavior of single individuals but also with the wealth distribution as a whole.

Nishiyama (2000) uses macroeconomic data to measure parental altruism in a model in which a parent and children interact strategically. The main focus of my paper is not to measure parental altruism, but to assess the quantitative implications of intergenerational transmission of bequests and earnings ability on wealth inequality. 
Hurd (1989) analyzes and estimates a life-cycle model with accidental and voluntary bequests. His estimates of the marginal utility from leaving bequests, which is constant by assumption, are small, and so are the implied desired bequests. These estimates are based on a sample of single, retired people, most of whom are widowers and have low levels of assets, and are thus consistent with the view that bequests are a luxury good.

\section{Some Facts about the United States and Sweden}

Including residential structures, plant and equipment, land, and consumer durables in my measure of capital, I obtain an average capital-to-GDP ratio of about 3 for the United States during the 1959-92 period ${ }^{1}$ (Auerbach and Kotlikoff (1995)) and about 2 for Sweden (Hansson (1989)).

Kotlikoff and Summers (1981) estimate that private transfers of wealth across generations account for at least $80 \%$ of the current value of total wealth. A recent study by Gale and Scholz (1994) estimates this number to be 60\%, including bequests and inter vivos transfers (adjusted for underreporting), but not college payments. The ratio of inheritances to wealth for Sweden comes from Laitner and Ohlsson (1997), who compute the current value of household inheritances in Sweden as a fraction of household wealth. The Swedish data seem to be of lower quality than the U.S. data and do not include inter vivos transfers. Hence, the numbers for Sweden are likely to be lower bounds for the actual numbers.

\begin{tabular}{|c|c|c|c|c|c|c|c|c|}
\hline \multirow{2}{*}{$\begin{array}{l}\text { Capital } \\
\text { GDP } \\
\text { ratio }\end{array}$} & \multirow{2}{*}{$\begin{array}{c}\text { Transfer } \\
\text { wealth } \\
\text { ratio }\end{array}$} & \multirow{2}{*}{$\begin{array}{c}\text { Wealth } \\
\text { Gini }\end{array}$} & \multicolumn{6}{|c|}{ Percentage wealth in the top } \\
\hline & & & $1 \%$ & $5 \%$ & $20 \%$ & $40 \%$ & $60 \%$ & $80 \%$ \\
\hline \multicolumn{9}{|c|}{ U.S. data } \\
\hline 3.0 & .60 & .78 & 29 & 53 & 80 & 93 & 98 & 100 \\
\hline \multicolumn{9}{|c|}{ Swedish data } \\
\hline 2.0 & $>.51$ & .73 & 17 & 37 & 75 & 99 & 100 & 100 \\
\hline
\end{tabular}

Table 1: Wealth.

The U.S. data on the wealth distribution are from the 1989 Survey of Finances (SCF) and refer to households 25 years of age and older. The distribution for 1992 is very similar.

\footnotetext{
${ }^{1}$ The wealth-to-GDP ratio for the United States is remarkably close to the capital-to-GDP ratio, varying between 2.9 in 1989 and 3.1 in 1991 .
} 
Wealth includes owner-occupied housing, other real estate, cash, financial securities, unincorporated business equity, insurance, and pension cash surrender value, and is net of mortgages and other debt. For Sweden, the wealth distribution data refer to 1984-85 (Palsson (1993)).

\begin{tabular}{|c|c|c|c|c|c|}
\hline \multirow[b]{2}{*}{$\begin{array}{l}\text { Gini } \\
\text { coeff. }\end{array}$} & \multicolumn{5}{|c|}{ Percentage earnings in the top } \\
\hline & $1 \%$ & $5 \%$ & $20 \%$ & $40 \%$ & $80 \%$ \\
\hline \multicolumn{6}{|c|}{ U.S. data } \\
\hline .46 & 6 & 19 & 48 & 72 & 98 \\
\hline \multicolumn{6}{|c|}{ Swedish data } \\
\hline .40 & 4 & 15 & 42 & 68 & 98 \\
\hline
\end{tabular}

Table 2: Gross earnings.

Table 2 is computed using data from the Luxembourg Income Study (LIS) data set, which collects income data sets from various countries (based on the March Current Population Survey for the United States) and makes them comparable. The table is computed using data for households whose head is 25 to 60 years of age, and the definition of gross earnings includes wages, salaries, and self-employment income. Tables 1 and 2 show that earnings display a much lower concentration than wealth.

Comparing earnings and wealth inequality across these two countries, we can see that the Swedish earnings distribution is less concentrated than the U.S. distribution, but the Gini coefficient for wealth is close in the two countries (.78 in the United States and .73 in Sweden). The high Gini coefficients for wealth result from different reasons. In the United States the richest $1-5 \%$ of people hold a large fraction of total wealth, $29 \%$, and the poorest $60 \%$ of the population hold $7 \%$ of total net worth. On the contrary, in Sweden the richest 1-5\% of people do not hold as much of total wealth, $17 \%$, but the poorest $60 \%$ of people hold only $1 \%$ of total net worth. This may be due to the fact that social security and unemployment benefits are more generous in Sweden than in the United States, and these social insurance programs are a disincentive to save, especially for people with low lifetime earnings. In fact, people for whom social security benefits are high compared to their lifetime income will not save for retirement in the presence of a redistributive social security system. Moreover, if security nets (such as unemployment insurance) are substantial, precautionary savings will 
be lower.

\section{The Model}

The economy is populated by an infinitely lived government and overlapping generations of people, who may differ in their productivity levels. The members of successive generations are linked by bequests and the children's inheritance of part of their parent's productivity. At age 20 each person enters the model and starts consuming, working, and paying labor and capital income taxes. At age 25 the consumer procreates. After retirement the agent no longer works but receives social security benefits from the government and interest from accumulated assets. The government taxes labor earnings, capital income, and estates and pays pensions to the retirees.

\section{A. Demographics}

During each model period, which is five years long, a continuum of people ${ }^{2}$ is born. I define age $t=1$ as 20 years old, age $t=2$ as 25 years old, and so on. After one model period, at $t=2$, the agent's children are born, and four periods later (when the agent is 45 years old) the children are 20 and start working. Since there are no inter vivos transfers in this model economy, all agents start off their working life with no wealth. Total population grows at a constant, exogenous rate $(n)$, and each agent has the same number of children. ${ }^{3}$ The agents retire at $t=t_{r}=9$ (i.e., when they are 65 years old) and die for sure by the end of age $T=14$ (i.e., before turning 90 years old). From $t=t_{r}-1$ (i.e., 60 years of age) to $T$, each person faces a positive probability of dying given by $\left(1-\alpha_{t}\right)$. Since death is assumed to be certain after age $T, \alpha_{T}=0$. The assumption that people do not die before 60 years of age reduces computational time and does not influence the results because the number of people dying between the ages of 20 and 60 is small.

Since I consider only stationary environments, the variables are indexed only by age, $t$, and the index for time is left implicit.

\footnotetext{
2In the theoretical sections, I use the terms "agent," "person," "consumer," and "household" interchangeably. Each household is taken to be composed of one person and dependent children.

${ }^{3}$ The number of children is thus $n^{5}$ if $n$ is the growth rate of the population over five years, or $n^{25}$ if $n$ is expressed in yearly terms.
} 


\section{B. Preferences and Technology}

Preferences are assumed to be time separable, with a constant discount factor. The utility from consumption in each period is given by $u\left(c_{t}\right)=c_{t}^{1-\sigma} /(1-\sigma)$.

Parents care about their selfish children. The particular form of altruism I consider is called warm glow: the parents derive utility from leaving a bequest (net of estate taxes) to their children. The utility from leaving a net bequest, $b_{t}$, is $\phi\left(b_{t}\right)$. Considering a more sophisticated form of altruism would increase the number of state variables (already four in this setup) and, in some cases, would generate strategic parent-child interaction.

In this economy all agents face the same exogenous age-efficiency profile, $\epsilon_{t}$, during their working years. This profile is estimated from the data and recovers the fact that productive ability changes over the life cycle. Workers also face stochastic shocks to their productivity level. These shocks are represented by a Markov process $\left\{y_{t}\right\}$ defined on $(Y, \mathcal{B}(Y))$ and characterized by a transition function $Q_{y}$, where $Y \subset \Re_{++}$and $\mathcal{B}(Y)$ is the Borel $\sigma$-algebra on $Y$. This Markov process is the same for all households. The total productivity of a worker of age $t$ is given by the product of the worker's stochastic productivity in that period and the worker's deterministic efficiency index at the same age: $y_{t} \epsilon_{t}$. The parent's productivity shock at age 40 is transmitted to children at age 20 according to a transition function $Q_{y h}$, defined on $(Y, \mathcal{B}(Y))$. What the children inherit is only their first draw; from age 20 on, their productivity $y_{t}$ evolves stochastically according to $Q_{y}$.

I assume that children cannot observe directly their parent's assets, but only their parent's productivity when the parent is 40 and the children are 15, that is, the period before they "leave home" and start working. Based on this information, children infer the size of the bequest they are likely to receive. I will discuss the relevance and the qualitative effects of relaxing all of these assumptions in Section 7.

The household can only invest in physical capital, at a rate of return $r$. The depreciation rate is $\delta$, so the gross-of-depreciation rate of return on capital is $r+\delta$. I assume also that the agents face borrowing constraints that do not allow them to hold negative assets at any time.

I assume that the United States is a closed economy with an aggregate production function $F(K, L)=A K^{\alpha} L^{1-\alpha}$, where $K$ is aggregate capital and $L$ is aggregate labor. I 
instead assume that Sweden is a small open economy, so the interest rate net of taxes is taken as exogenous and equal to that of the United States. For each country, I normalize the units of labor and of the good so that, in the steady state, the average labor earnings of a worker per period and the wage are both one.

\section{Government}

The government taxes labor earnings, capital income, and estates to finance the exogenous public expenditure and to provide pensions to the retired agents.

Labor earnings are taken as exogenous and calibrated to the data, matching the aftertax Gini coefficient. Since the U.S. tax system is progressive, this Gini coefficient is lower than the one computed from pre-tax labor earnings. In the model, I introduce a constant tax rate $\tau_{l}$ in order to balance the government budget, while all the progressive features of the tax system are already reflected in the calibrated after-tax earnings distribution.

Income from capital is taxed at a flat rate $\tau_{a}$. Estates larger than a given value $e x_{b}$ are taxed at rate $\tau_{b}$ on the amount in excess of $e x_{b}$.

The structure of the social security system is the following: the retired agents receive a lump-sum transfer from the government each period until they die. The amount of this transfer is linked to the average earnings of a person in the economy.

\section{The Household's Recursive Problem}

I consider an environment in which, during each period, a $t$-year-old agent chooses consumption $c$ and risk-free asset holdings for the next period, $a^{\prime}$. For given prices, the state variables for an agent are denoted by $x=(t, a, y, y p)$. These variables indicate, respectively, the agent's age $(t)$, the agent's assets carried from the previous period $(a)$, the agent's current productivity process realization $(y)$, and the value of the agent's parent's productivity at age 40 until the agent inherits and zero thereafter (yp). This last variable takes on two purposes. First, when it is positive, it is used to compute the probability distribution on bequests that the household expects from the parent. Second, it distinguishes the agents who have already inherited, for whom I set $y p=0$, from those who have not, for whom $y p$ is strictly positive. The agents inherit bequests only once in a lifetime, at a random date which depends on their parent's death. Since there is no market for annuities, part of the bequests the child receives 
are accidental bequests, linked to the fact that people's life span is uncertain and people therefore accumulate precautionary savings to offset the life-span risk. The optimal decision rules are functions for consumption, $c(x)$, and next period's asset holdings, $a^{\prime}(x)$, that solve the dynamic programming problem described below.

(i) From age $t=1$ to age $t=3$ (from 20 to 30 years of age), the agent works and will survive with certainty until next period. Moreover, the agent does not expect to receive a bequest soon because his or her parent is younger than 60 and will survive at least one more period for sure. Since the law of motion of $y p$ is dictated by the death probability of the parent, for this subperiod $y p^{\prime}=y p$. Thus,

(1) $\quad V(t, a, y, y p)=\max _{c, a^{\prime}}\left\{u(c)+\beta E_{t} V\left(t+1, a^{\prime}, y^{\prime}, y p\right)\right\}$

subject to

(2) $\quad c \leq\left[1+r\left(1-\tau_{a}\right)\right] a+\left(1-\tau_{l}\right) \epsilon_{t} y$

(3) $\quad a^{\prime}=\left[1+r\left(1-\tau_{a}\right)\right] a-c+\left(1-\tau_{l}\right) \epsilon_{t} y$.

The interest rate on assets is denoted by $r$, and the evolution of $y^{\prime}$ is described by the transition function $Q_{y}$.

(ii) From $t=4$ to $t=8$ (from 35 to 55 years of age), the worker will survive for sure up to the next period. However, the agent's parent is at least 60 years old and faces a positive probability of dying any period; hence, a bequest might be received at the beginning of the next period. Let $I_{y p>0}$ be the indicator function for $y p>0$; it is one if $y p>0$ and zero otherwise. Thus,

(4) $V(t, a, y, y p)=\max _{c, a^{\prime}}\left\{u(c)+\beta E_{t} V\left(t+1, a^{\prime}, y^{\prime}, y p^{\prime}\right)\right\}$

subject to (2) and

(5) $\quad a^{\prime}=\left[1+r\left(1-\tau_{a}\right)\right] a-c+\left(1-\tau_{l}\right) \epsilon_{t} y+b^{\prime} I_{y p>0} I_{y p^{\prime}=0}$ 
(6) $y p^{\prime}= \begin{cases}y p & \text { with probability } \alpha_{t+5} \\ 0 & \text { with probability }\left(1-\alpha_{t+5}\right)\end{cases}$

where $E_{t}$ is the conditional expectation based on the information available at time $t$.

The conditional distribution of the bequest a person expects in case of parental death is denoted by $\mu_{b}(x ;.) .{ }^{4}$ In equilibrium this distribution must be consistent with the parent's behavior. Since the evolution of the state variable yp is dictated by the death process of the parent, $y p^{\prime}$ jumps to zero with probability $\alpha_{t+5}$. (Five periods is the difference in age between parents and their children.) I assume the following processes to be independent: the survival/death of the decision maker; the survival/death of the parent; the size of the bequest received from the parent, conditional on the parent dying; and the future labor earnings, conditional on the current earnings.

(iii) The subperiod $t_{r}-1$ (60 years old) is the period before retirement. The agent starts facing a positive probability of dying, in which case the agent derives utility from bequeathing his or her assets. Define after-tax bequests as $b\left(a^{\prime}\right)=a^{\prime}-\tau_{b} \cdot \max \left(0, a^{\prime}-e x_{b}\right)$. Thus,

(7) $V(t, a, y, y p)=\max _{c, a^{\prime}}\left\{u(c)+\alpha_{t} \beta E_{t} W\left(t+1, a^{\prime}\right)+\left(1-\alpha_{t}\right) \phi\left(b\left(a^{\prime}\right)\right)\right\}$

where

(8) $\phi(b)=\phi_{1}\left(1+\frac{b}{\phi_{2}}\right)^{1-\sigma}$

subject to (2), (5), and (6). The term $\phi_{1}$ reflects the parent's altruism toward the children, while $\phi_{2}$ measures the extent to which bequests are a luxury good. ${ }^{5}$

(iv) From $t_{r}$ to $T$ (from 65 to 85 ), is the period after retirement. The agent does not inherit after turning 65 because the agent's parent is already dead at that time. Moreover, I assume that people no longer work after retirement and live off pensions and interest.

\footnotetext{
${ }^{4}$ The probability distribution $\mu_{b}$ depends on $x$ only through $t$ and $y p$, not through $y$.

${ }^{5}$ Even with full altruism, preferences over bequests and consumption would not be homothetic. This is because bequests add to the permanent income of the children, which is already positive.
} 
This implies that I can drop two state variables from the retired people's value function, $y$ and $y p$, and that the only uncertainty the retired agents face is the time of their death:

(9) $W(t, a)=\max _{c, a^{\prime}}\left\{u(c)+\alpha_{t} \beta W\left(t+1, a^{\prime}\right)+\left(1-\alpha_{t}\right) \phi\left(b\left(a^{\prime}\right)\right)\right\}$

subject to (8) and

(10) $c \leq\left[1+r\left(1-\tau_{a}\right)\right] a+p$

(11) $a^{\prime}=\left[1+r\left(1-\tau_{a}\right)\right] a-c+p$

where $p$ is the pension payment from the government. The terminal period value function $W(T+1, a)$ is set to equal $\phi(b(a))$.

\section{E. Definition of Stationary Equilibrium}

A stationary equilibrium is given by

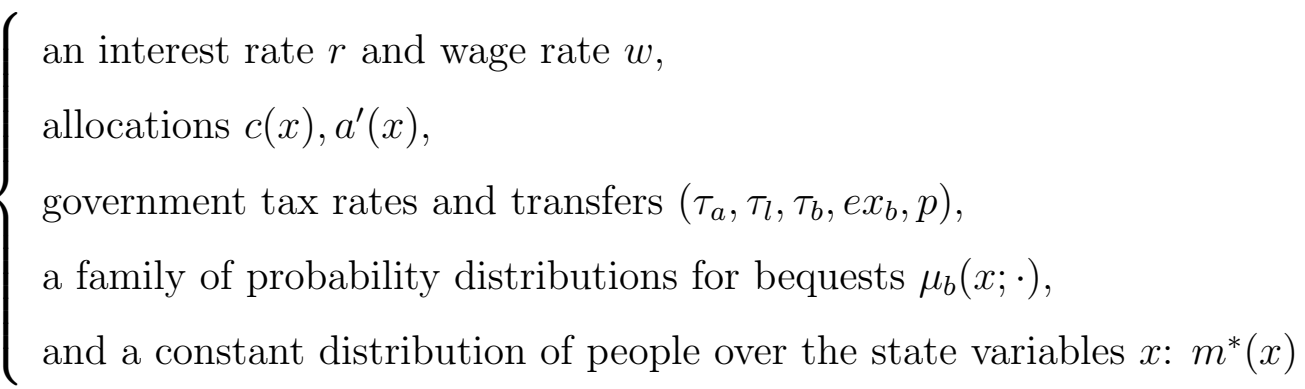

such that the following hold:

(i) Given the interest rate, the wage, government tax rates and transfers, and the expected bequest distribution $\mu_{b}(x ; \cdot)$, the functions $c(x)$ and $a^{\prime}(x)$ solve the above described maximization problem for a household with state variables $x$.

(ii) The tax rate $\tau_{l}$ is chosen so that the government budget constraint balances at every 
period:

$$
\begin{aligned}
g=\int[ & \tau_{a} r a+\tau_{l} \epsilon_{t} y I_{t<t_{r}}-p I_{t \geq t_{r}} \\
& \left.+\tau_{b}\left(1-\alpha_{t-1}\right) \cdot \max \left(0, a^{\prime}(x)-e x_{b}\right)\right] d m^{*}(x) .
\end{aligned}
$$

(iii) The invariant distribution of households over the state variables for this economy, $m^{*}$, is a fixed point of the operator $R_{M}$ defined in Appendix A1: $R_{M} m^{*}=m^{*}$. I normalize $m^{*}$ so that $m^{*}(X)=1$, which implies that $m^{*}(\chi)$ is the fraction of people alive that are in a state $\chi \in \mathcal{X}$.

(iv) The United States is treated as a closed economy. Aggregate capital $K$ is given by $\int a d m^{*}(x)$. Aggregate effective labor is denoted by $L$. The wage $w$ is normalized to be one at the steady state. Given that I assume a Cobb-Douglas aggregate production function, for given equilibrium $r$, I require that the share of income going to capital is $\alpha$, that is, $\frac{(r+\delta) K}{(r+\delta) K+w L}=\alpha$, where $\alpha$ is determined by the calibration.

Sweden is treated as a small open economy, so $r$ is taken as exogenous. The wage is normalized to one, and $K$ is given by $\int a d m^{*}(x)$. In this case, $K$ represents the average wealth held by Swedish citizens (in Sweden and abroad), which may differ from average capital present in Sweden (held by Swedish people and foreigners).

(v) The family of expected bequest distributions $\mu_{b}(x ; \cdot)$ is consistent with the bequests that are actually left by the parents. See Appendix A2 for a formal characterization of this statement.

\section{The Experiments}

To understand the quantitative importance of these intergenerational links, I construct several simulations. I start with an experiment in which the model is stripped of all intergenerational links: an overlapping-generations model with life-span and earnings uncertainty. The accidental bequests left by the people who die prematurely are seized by the government 
and equally redistributed to all people alive. ${ }^{6}$ The idea is to see how much wealth inequality can be generated by the life-cycle structure when only life-span and earnings uncertainty are activated. In the second experiment unplanned bequests are distributed to the children of the deceased, rather than equally to everybody alive. This is meant to assess whether an unequal distribution of estates is quantitatively important when all bequests are involuntary. The third experiment adds inheritance of ability to the second one. In the fourth experiment parents care about leaving bequests to their children, but there is no inheritance of ability. The fifth exercise activates both the bequest motive and the parent's productivity inheritance in order to evaluate the importance of both intergenerational links jointly.

To be consistent across experiments, I use the same initial distribution of productivity for 20-year-old workers in all simulations for a given country. To do so, for each country I compute the initial aggregate distribution of productivity implied by the experiment with inheritance of productivity and use it to initialize all the 20-year-old workers in the simulations without productivity inheritance.

\section{Calibration}

I distinguish two sets of parameters: those that can be estimated independently of the model or are based on estimates provided by other studies (Table 3), and those that I choose so that the model-generated data match a given set of targets (Table 4). Appendix A3 provides more details about the calibration.

Table 3. The $\alpha_{t}$ 's are the vectors of conditional survival probabilities for people older than $60, \epsilon_{t}$ is the age-efficiency profile vector, $n$ is the rate of population growth, $g$ is government expenditures, and $\tau_{a}$ is the capital income tax.

The logarithm of the productivity process is assumed to be an $\operatorname{AR}(1)$ with persistence $\rho_{y}$ and variance $\sigma_{y}^{2}$. For the United States these two parameters are estimated from Panel Study on Income Dynamics (PSID) data, aggregated over five years in order to be consistent with the model period. ${ }^{7}$

\footnotetext{
${ }^{6}$ This exercise uses Huggett's setup but adapts it to the length of the periods and the productivity process that I use throughout this paper in order to make the results comparable to the other simulations I run. I cannot use the same time period and income process that Huggett uses, since the simulations with altruism require a higher number of state variables and the model would require huge computing resources to solve.

${ }^{7}$ I am very grateful to Joe Altonji and Ernesto Villanueva for kindly providing me with these estimates.
} 


\begin{tabular}{ccc}
\hline Parameter & U.S. calibration & Swedish calibration \\
\hline$\alpha_{t}$ & vector & vector \\
$\epsilon_{t}$ & vector & vector \\
$n$ & $1.2 \%$ yearly & $0.8 \%$ yearly \\
$g$ & $18 \%$ of GDP & $25 \%$ of GDP \\
$\tau_{a}$ & $20 \%$ & $30 \%$ \\
$\rho_{y}$ & .85 & .85 \\
$\sigma_{y}^{2}$ & .30 & .1429 \\
$\rho_{y h}$ & .677 & .677 \\
$\sigma_{y h}^{2}$ & .37 & .1762 \\
$\sigma$ & 1.5 & 1.5 \\
\hline
\end{tabular}

Table 3: Parameters estimated independently of the model or provided by other studies.

The logarithm of the productivity inheritance process (for yp) is also assumed to be an $\operatorname{AR}(1)$ with persistence $\rho_{y h}$ and variance $\sigma_{y h}^{2}$. I take $\rho_{y h}$ from Zimmerman (1992), and for the United States I choose $\sigma_{y h}^{2}$ to match a Gini coefficient of .44 for earnings. These assumptions generate an increase in earnings inequality over the life cycle that is consistent with the data.

The persistence of the productivity and productivity inheritance processes are taken to be the same for Sweden and the United States. Björklund and Jäntti (1997) estimate the degree of intergenerational income mobility in Sweden and do not reject the hypothesis that it is the same as in the United States. As for the variances, in Sweden more generous social insurance programs partially insure households from idiosyncratic shocks and decrease earnings inequality. (More so than in the United States; see De Nardi, Ren, and Wei (2000).) To recover this effect, I reduce both $\sigma_{y}$ and $\sigma_{y h}$ for Sweden to match a Gini coefficient for earnings of .33 , while imposing that the ratio of $\sigma_{y}$ and $\sigma_{y h}$ for Sweden to be equal to the corresponding ratio for the United States.

I take risk aversion, $\sigma$, to be the same in the United States and in Sweden. The value that I use in the calibration is from Attanasio et al. (1999) and Gourinchas and Parker (2002), who estimate it using consumption data. This value falls in the range (1-3) commonly used in the literature.

Table 4. The remaining parameters are chosen to match features of the respective economies as follows. The rate $r$ is the interest rate on capital, net of depreciation and 


\begin{tabular}{ccc}
\hline Calibrated & & \\
Parameter & U.S. calibration & Swedish calibration \\
\hline$r$ & $6 \%$ & $6.86 \%$ \\
$p$ & $40 \%$ average earnings & $47-50 \%$ average earnings \\
$\tau_{b}$ & $10 \%$ & $15 \%$ \\
$e x_{b}$ & 40 years of average earnings & 10 years average earnings \\
$\beta$ & $.95-.97$ & $.95-.97$ \\
$\phi_{1}$ & -9.5 & -9.5 \\
$\phi_{2}$ & 11.6 & 11.6 \\
\hline
\end{tabular}

Table 4: Parameters used to match some features in the data.

gross of taxes. For the United States, I fix it at $6 \%$, so that the corresponding capital share of output turns out to be .36 across the various simulations. This choice is motivated by long-run observations on capital shares in the U.S economy (Cooley and Prescott (1995)).

Given that I assume that Sweden is a small open economy, I take its interest rate to be $6.86 \%$ so that the interest rates net of taxes in the two countries coincide.

Pensions, $p$ : for each country, the social security replacement rates are chosen such that the ratios of government transfers to GDP generated by the model are consistent with the ratio reported in the Economic Report of the President (1998) for the United States and with the one (net of taxes) reported in OECD Economic Surveys, 1998-1999: Sweden (1999) for 1996 (respectively, 7\% and 12\%). The implied replacement rate for the United States is $40 \%$, across all experiments, which is a number similar to those used in many papers on social security. The implied replacement rate for Sweden is $50 \%$ in the experiments without a bequest motive, and $47 \%$ in the other two. Using the same replacement rate of $50 \%$ in all simulations for Sweden would generate very similar wealth distributions and a marginally lower capital-output ratio.

The rate $\tau_{b}$ is the tax rate on estates that exceed the exemption level $e x_{b}$. For the United States I set these parameters to match the observed ratio of estate tax revenues to GDP, and the proportion of estates that pay estate taxes, $1.5 \%$ in the experiment with both intergenerational links.

In Sweden taxes are paid on inheritances, rather than on estates. It is therefore more difficult than in the United States to define the statutory exemption level. The combined 
choice of $\tau_{b}$ and $e x_{b}$ matches the revenues from bequests and gift taxes as a fraction of GDP in the experiment with both intergenerational links. I do sensitivity analysis on these parameters for Sweden and find that the results do not vary significantly for reasonable values of these parameters.

For the United States, in each experiment I choose the discount factor, $\beta$, to match a capital-to-GDP ratio of 3 . On a yearly basis, $\beta$ turns out to be .97 in the simulation in which accidental bequests are equally distributed, .96 in the two experiments with accidental bequests (one with and one without productivity inheritance), and .95 in the two simulations with bequest motives, with and without productivity inheritance.

I use $\phi_{1}$ to match a transfer wealth share of $60 \%$ in the U.S. simulation with both intergenerational links.

Many people leave estates of little or no value: according to Hurd and Smith (1999), the average bequest left by single decedents at the lowest 30th percentile was $\$ 2,000$ (Asset and Health Dynamics Among the Oldest Old (AHEAD) data set, 1993-95). Median household income in 1994 was $\$ 32,264$ (U.S. Census Web site, CPS data). I choose $\phi_{2}$ to match that ratio in the model with both links. Using the average bequest left by singles rather than the one for all decedents (which turns out to be $\$ 10,000$ ) is a more sensible choice because typically a surviving spouse inherits a share of the estate, which will be partly consumed before finally being left to the couple's children.

I choose to use the same parameter values for $\phi_{1}$ and $\phi_{2}, \tau_{b}$ and $e x_{b}$, in the simulations with bequest motive only or with both intergenerational links in order to disentangle the increase in wealth inequality due to the two links when the preference parameters for bequests and estate taxation are the same.

The preference parameters for Sweden are assumed to be equal to those for the United States.

\section{Results}

Tables 5 and 6 summarize the results for the United States and Sweden. ${ }^{8}$

\footnotetext{
${ }^{8}$ For all experiments I exclude 20 -year-old people from the computations on the wealth distribution because I assume that people start off with zero wealth, and hence I do not propose a theory of the distribution of wealth for them. To explain the data for 20-year-old people, a theory of inter vivos transfers would, in my
} 


\begin{tabular}{|c|c|c|c|c|c|c|c|}
\hline \multirow{2}{*}{$\begin{array}{l}\text { Transfer } \\
\text { wealth } \\
\text { ratio }\end{array}$} & \multirow{2}{*}{$\begin{array}{c}\text { Wealth } \\
\text { Gini }\end{array}$} & \multicolumn{5}{|c|}{ Percentage wealth in the top } & \multirow{2}{*}{$\begin{array}{c}\text { Percentage with } \\
\text { negative or } \\
\text { zero wealth }\end{array}$} \\
\hline & & $1 \%$ & $5 \%$ & $20 \%$ & $40 \%$ & $60 \%$ & \\
\hline \multicolumn{8}{|c|}{ U.S. data } \\
\hline .60 & .78 & 29 & 53 & 80 & 93 & 98 & $5.8-15.0$ \\
\hline \multicolumn{8}{|c|}{ No intergenerational links, equal bequests to all } \\
\hline .67 & .67 & 7 & 27 & 69 & 90 & 98 & 17 \\
\hline \multicolumn{8}{|c|}{ No intergenerational links, unequal bequests to children } \\
\hline .38 & .68 & 7 & 27 & 69 & 91 & 99 & 17 \\
\hline \multicolumn{8}{|c|}{ One link: productivity inheritance } \\
\hline .38 & .69 & 8 & 29 & 70 & 92 & 99 & 17 \\
\hline \multicolumn{8}{|c|}{ One link: parent's bequest motive } \\
\hline .55 & .74 & 14 & 37 & 76 & 95 & 100 & 19 \\
\hline \multicolumn{8}{|c|}{ Both links: parent's bequest motive and productivity inheritance } \\
\hline .60 & .76 & 18 & 42 & 79 & 95 & 100 & 19 \\
\hline
\end{tabular}

Table 5: Results for the U.S. calibration.

\section{A. No Intergenerational Links}

Line 2 in Table 5 shows that an overlapping-generations model with no dynastic links and equal distribution of bequests has serious difficulties in generating enough skewness to match the U.S. distribution of wealth. The lower tail of the wealth distribution is too fat, and its upper tail is far too thin.

The large number of people at low asset levels is a common problem of overlappinggenerations models. The households are born without savings that could be used to absorb negative productivity shocks; hence, all young consumers who get a bad productivity shock hit the borrowing constraint. As households work and get older, they gradually accumulate assets for self-insurance purposes and to finance consumption during retirement and the fraction of people with low wealth gradually declines until retirement.

As for the upper tail, the richest $1 \%$ and $5 \%$ of people in the model hold, respectively, only $7 \%$ and $27 \%$ of total assets, compared with $29 \%$ and $53 \%$ in the data. The households save to buffer against income shocks, for retirement, and to self-insure against the risk of having a long life span. These saving motives are not sufficient to generate huge asset holdings

opinion, be required. The 20-year-olds are also excluded from the U.S. data on the distribution. 


\begin{tabular}{|c|c|c|c|c|c|c|c|c|}
\hline \multirow{2}{*}{$\begin{array}{l}\text { Wealth } \\
\text { GDP } \\
\text { ratio }\end{array}$} & \multirow{2}{*}{$\begin{array}{l}\text { Transfer } \\
\text { wealth } \\
\text { ratio }\end{array}$} & \multirow{2}{*}{$\begin{array}{c}\text { Wealth } \\
\text { Gini }\end{array}$} & \multicolumn{5}{|c|}{ Percentage wealth in the top } & \multirow{2}{*}{$\begin{array}{c}\text { Percentage with } \\
\text { negative or } \\
\text { zero wealth }\end{array}$} \\
\hline & & & $1 \%$ & $5 \%$ & $20 \%$ & $40 \%$ & $60 \%$ & \\
\hline \multicolumn{9}{|c|}{ Swedish data } \\
\hline 2.0 & $>.51$ & .73 & 17 & 37 & 75 & 99 & 100 & 30 \\
\hline \multicolumn{9}{|c|}{ No intergenerational links, equal bequests to all } \\
\hline 2.0 & .73 & .67 & 7 & 26 & 68 & 90 & 98 & 22 \\
\hline \multicolumn{9}{|c|}{ No intergenerational links, unequal bequests to children } \\
\hline 1.9 & .42 & .69 & 7 & 28 & 71 & 93 & 99 & 26 \\
\hline \multicolumn{9}{|c|}{ One link: productivity inheritance } \\
\hline 1.9 & .43 & .70 & 8 & 30 & 72 & 93 & 100 & 28 \\
\hline \multicolumn{9}{|c|}{ One link: bequest motive } \\
\hline 1.5 & .46 & .74 & 9 & 32 & 76 & 96 & 100 & 33 \\
\hline \multicolumn{9}{|c|}{ Both links: bequest motive and productivity inheritance } \\
\hline 1.5 & .47 & .75 & 10 & 34 & 78 & 96 & 100 & 33 \\
\hline
\end{tabular}

Table 6: Results for the Swedish calibration.

for parameterizations of the relevant processes that are consistent with the data.

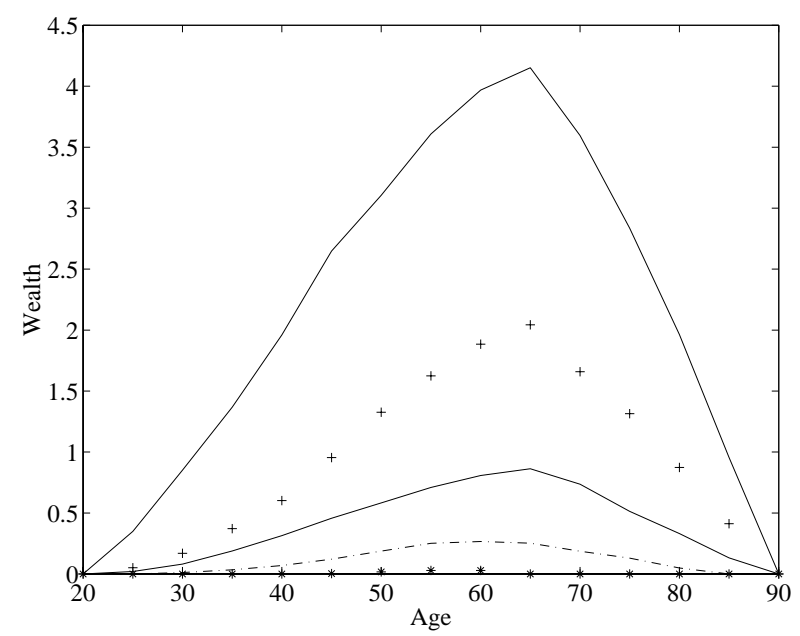

Figure 1: U.S. wealth .1, .3, .5, .7, .9, .95 quantiles, by age. No links, equal bequests to all.

The overlapping-generations model with no intergenerational links also fails to recover the age-asset profile observed in the data. All households in the model economy (Figure 1) run down their assets during retirement until they are left with zero wealth at the time we assume they die for sure. This implies a much larger dissaving than observed in the data, especially for the richer households. Dynan, Skinner, and Zeldes (1996) find that the richest 
retirees (defined as those in the richest quintile or in the top $5 \%$ or $1 \%$ of the lifetime income distribution) not only keep substantial amounts of assets at advanced ages, but also keep saving a larger fraction of their income than the poorest retirees. Based on their empirical findings, the authors argue, "The results clearly rule out models that imply that saving is proportional to permanent income." They argue further that "These results suggest that in the top $1 \%$ (or top $5 \%$ ) of the population the motives for saving, in particular for bequests, might be different from their less affluent (but still high income) colleagues."

The transfer-wealth ratio appears high for this simulation because all living agents receive a transfer every year, starting at age 20 (rather than at age 54 on average, as it happens with more realistic timing of bequests), and this measure includes interest from received transfers. This bias becomes clearer in line 3, which corresponds to the model economy in which accidental bequests are distributed to the children of those who die. In this case, the measure declines from .67 to .38 , even though the aggregate amount of bequests left in every period is almost the same.

Compared to the U.S. calibration, the households in the Swedish model economy face less earnings uncertainty and a higher social security replacement rate. The first element reduces precautionary saving, and the second one reduces life-cycle saving. Given that I assume Swedish people to be as patient as those in the United States, the model predicts a lower wealth-to-GDP ratio than in the United States. The distribution of wealth shows that, even in Sweden, the basic version of the model generates an upper tail of the wealth distribution which is too thin; the richest $1 \%$ of people hold only $7 \%$ of total wealth, compared with $14 \%$ in the data. Unlike the results for the U.S. model economy, the model for Sweden does not generate too many people at zero wealth.

Line 3 in Tables 5 and 6 displays the experiment in which accidental bequests are inherited by the children of the deceased, rather than being distributed equally to all living people. Comparing lines 2 and 3, we can see that distributing accidental bequests unequally, rather than equally, does not significantly increase wealth concentration in either country. The intuition is the following: some people in the economy inherit some wealth, other people do not, but nobody cares about leaving bequests. Without a bequest motive, even highincome households dissave quickly after retirement. The age-asset profiles for the various 
quantiles of the wealth distribution almost coincide with those generated by the previous experiment. In this economy, the large bequests are the ones left by 65 -year-old people who die prematurely. Older people, even if they were rich at age 65, keep few assets and leave small or no bequests when they die at advanced ages. The likelihood that several generations of the same family die around age 65 is very small. For this reason this model fails to generate the intergenerational transmission of large estates observed in the data.

\section{B. With Intergenerational Links}

Line 4 in Tables 5 and 6 shows that introducing productivity inheritance in the model with accidental bequests has small effects on wealth inequality. The fraction of total wealth held by the richest $1 \%$ of people increases from $7 \%$ to $8 \%$ in both countries. More productive parents tend to have more productive children, who, on average, receive larger bequests. However, this effect is small because just inheriting a higher productivity level from their parents does not make people choose higher saving rates, which is the mechanism that leads to the accumulation of the large fortunes observed in the data.

Even if the parameters in the bequest function were not chosen to generate more wealth concentration, we can see from line 5 in Tables 5 and 6 that the introduction of the bequest motive leads to a large increase in the concentration of wealth. In the simulations for the United States, the fraction of total wealth held by the people in the upper tail of the distribution increases significantly. The richest $1 \%$ of the population holds $14 \%$ of total wealth, and the richest $5 \%$ holds $37 \%$ of total wealth. In the simulations for Sweden, including the bequest motive increases the share of wealth held by the richest $1 \%$ of people from $7 \%$ to $9 \%$ and increases the share held by the top $5 \%$ from $26 \%$ to $32 \%$.

The intuition for why this happens is that the introduction of a nonhomothetic bequest motive makes bequests a luxury good. Households that either have high lifetime income or receive large bequests, or both, choose a higher saving rate, build up large estates, and keep a significant amount of assets even at advanced ages. These households, therefore, are more likely to leave large bequests when they die. This mechanism explains the emergence of the large estates that are accumulated by more than one generation of savers and are transmitted because of altruism. 


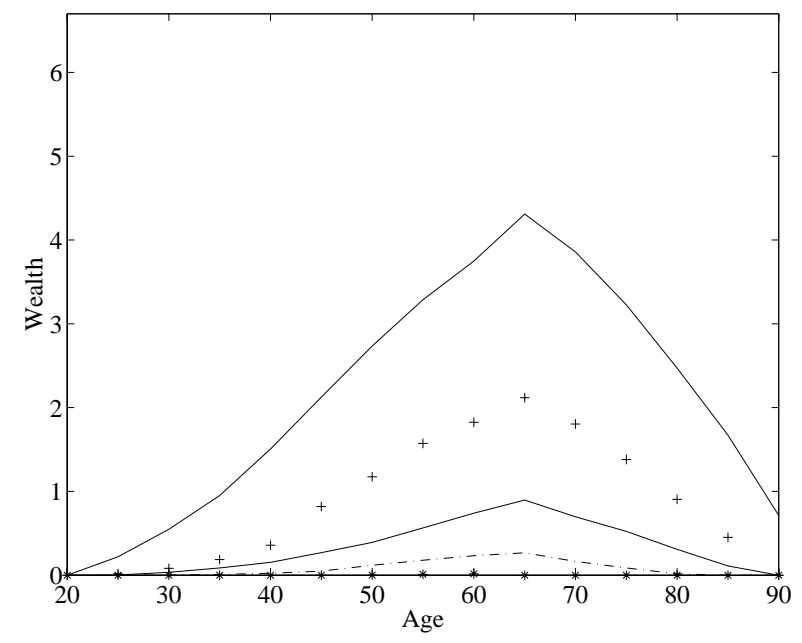

Figure 2: U.S. wealth .1, .3, .5, .7, .9, .95 quantiles, by age. Experiment with bequest motive only.

The age-asset profiles for various quantiles of the U.S. wealth distribution are displayed in Figure 2. In this figure notice a substantial difference in the main motives that lead the households to save. The median household saves mostly for retirement: the peak in its wealth holdings occurs at age 65, and if the household reaches the age of 85 , it consumes all of its assets (before dying at age 90) and does not leave any bequest. The median consumer leaves mostly unintended bequests. This becomes clearer when we compare the age-asset profiles for the poorest $10 \%, 30 \%$, and $50 \%$ with the model with no bequest motive (Figure 1): the profiles are very close.

At the top of the wealth distribution, a significant part of wealth is accumulated in order to leave bequests, and large bequests are left even when the parents die in advanced age. Comparing these top quantiles with those in the model with no altruistic links, we see how the introduction of a bequest motive produces an age-wealth profile for the retirees that is consistent with Dynan, Skinner, and Zeldes' (1996) findings. This is another feature of the model that is not matched by construction, but should be seen as a test of the model and its calibration.

Line 6 in Tables 5 and 6 refers to the experiment in which both intergenerational links are activated. This version of the model does an even better job of matching the observed skewness in asset holdings. In the simulations for the United States, the richest $1 \%$ of the population holds $18 \%$ of total wealth, up from $14 \%$ in the previous simulation, and the 
richest $5 \%$ holds $42 \%$ of total wealth, up from $37 \%$. The intergenerational transmission of productivity helps further in matching the top $20 \%$ of the wealth distribution for Sweden: the shares held by the richest $1 \%, 5 \%$, and $10 \%$ increase to $10 \%, 32 \%$, and $52 \%$, respectively.

When both intergenerational links are present, parents and children are linked not only by the bequest the parent intends to leave to the children, but also through transmission of productivity. Success in the workforce is now correlated across generations, and more productive parents accumulate larger estates and leave their bequests to their children who are, in turn, more productive than average in the workforce.

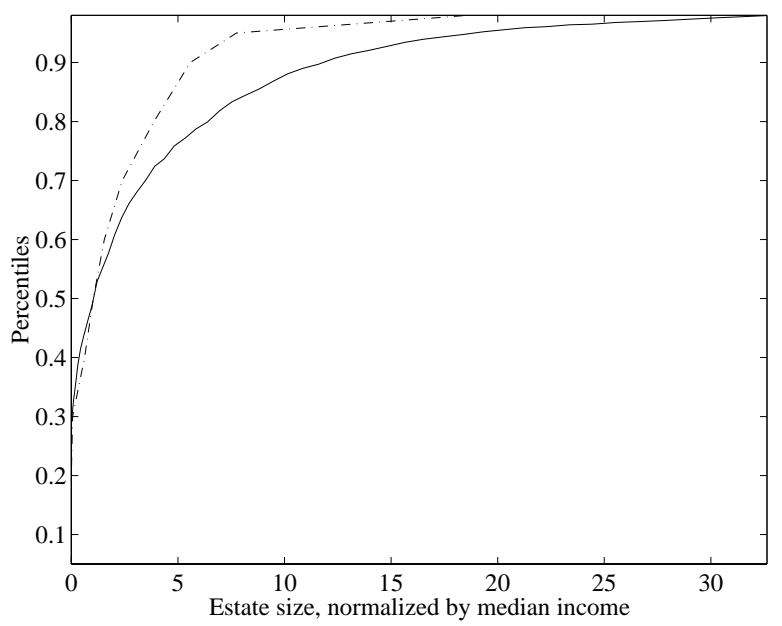

Figure 3: Cumulative distribution of estates, solid=model, dash-dot=AHEAD data.

To further gauge the ability of the model to explain the households' saving decisions, it is useful to compare other implications of the model to the data. I now look at the estate distribution and the elasticity of bequests to permanent income.

Figure 3 displays the cumulative distribution of estates implied by the model and the distribution that Hurd and Smith (1999) report from the AHEAD data for single decedents. The size of the estates is normalized by median household income. One parameter of the model was chosen so that the two distributions match at one point: the 30th percentile. The estate distribution generated by the model actually compares very well to the AHEAD data until the 70th percentile of the estate distribution. From that point on, the model predicts larger bequests than those observed in the AHEAD data. The discrepancy is partly due to the fact that AHEAD misses some large estates. As Davies and Shorrocks (2000) point out, 
over-sampling the rich is necessary to obtain a good representation of the asset holdings of the richest.

The model's implications about the elasticity of the old people's savings to permanent income are consistent with recent microeconomic estimates. Altonji and Villanueva (2002) use U.S. data from the PSID to estimate the effect of an increase of one dollar of permanent income on the asset holdings of the 70-year-old people. They find that this effect is rather small. To check whether this can be consistent with a model with voluntary bequests such as mine, they run the same regressions on the actual data and on data simulated using the models in this paper for the United States. They find that the effect of a dollar of permanent income on the old people's savings generated by my model with voluntary bequests is consistent with the magnitudes that they estimate in the data.

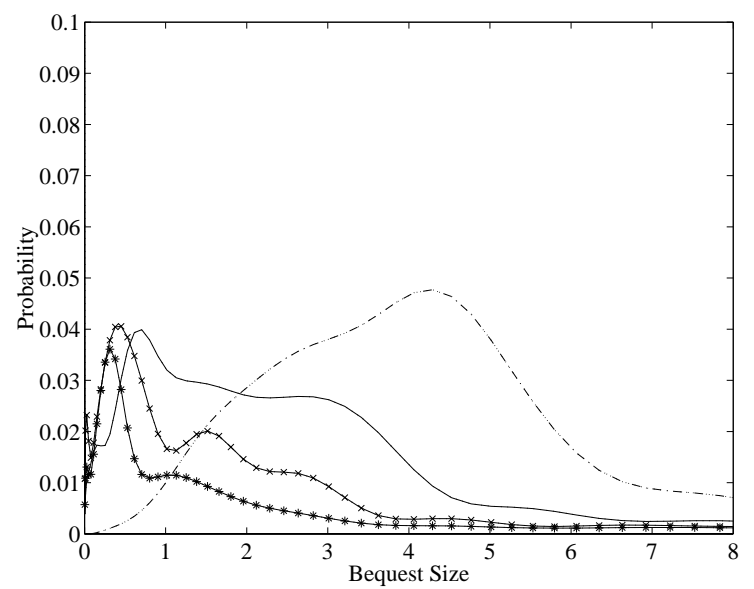

Figure 4: U.S. calibration. Strictly positive range of the expected bequest distribution at age 40 , conditional on the productivity of the parent.

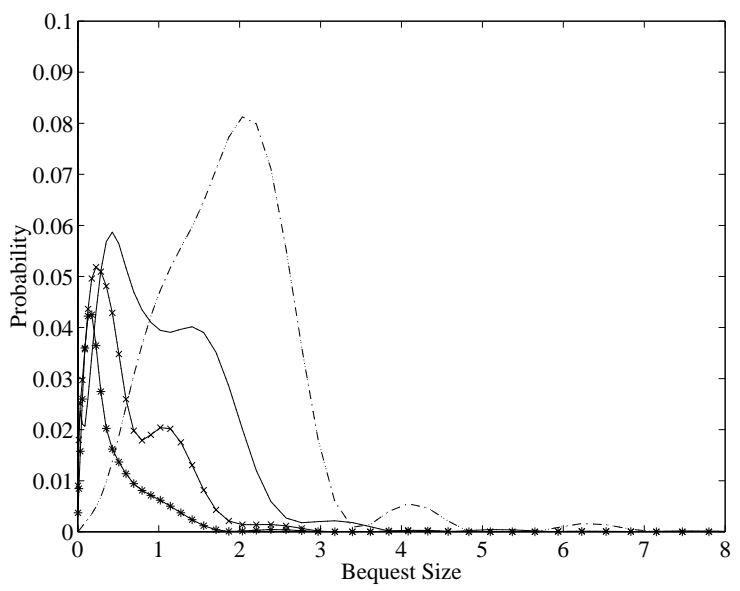

Figure 5: Swedish calibration. Strictly positive range of the expected bequest distribution at age 40, conditional on the productivity of the parent.

Now look at some of the features generated by the model to better understand its functioning. Figure 4 displays the strictly positive range of the bequest distribution for a 40-year-old person, conditional on the person's parent's observed productivity level, should the parent die during that period. At that age, the probabilities of receiving zero bequests are, respectively, $54 \%, 27 \%, 4 \%$, and $0 \%$, for people with parents in the lowest, second lowest, second highest, and highest productivity levels. The average bequests expected are, respectively, 3, 5, 10, and 21 years of average labor earnings. Even in the presence of a 
bequest motive, the parents run down their assets after retirement, so the expected bequest declines. The fraction of people whose parent lives up to the final age of the model economy and who do not receive a positive bequest are 97\%,95\%, 90\%, and 56\%, respectively. The average bequest that they expect at that point in life is about 1.4, 1.7, 2.6, and 6.6 years of average labor earnings.

Figure 5 shows the strictly positive range of the bequest distribution for 40-year-old Swedish agents, should their parent die this period. For people whose parent was at the lowest productivity level at age 40, the average bequest is 0.6 years of average labor earnings, and the probability of receiving no intergenerational transfer is $65 \%$. For those whose parent was at the highest productivity level at age 40, the average bequest is 9 years of average labor earnings, and the probability of receiving no intergenerational transfer is $0 \%$. Compared to the U.S. simulation, the average bequest size for all parents' levels of ability is lower.

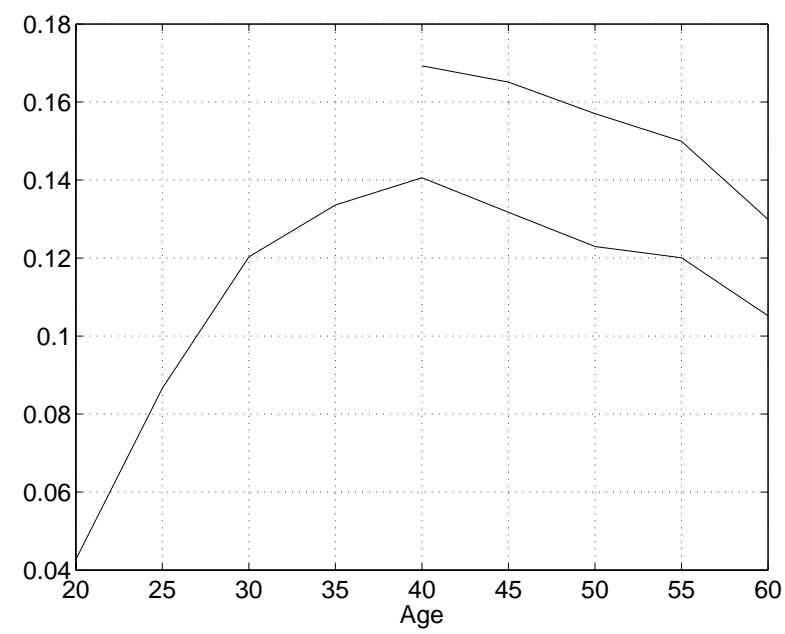

Figure 6: U.S. calibration. Saving rate for households who expect to inherit or not. Experiment with bequest motive only.

Figure 6 compares the saving behavior of the average U.S. agent who expects to receive some bequest with the agent's behavior in the hypothetical case in which the agent does not expect to receive a bequest. The fact that a parent's assets are not observable influences the saving behavior of people who have not yet inherited. Since in this economy children do not become orphans before age 40 and everybody attributes positive probability to receiving some bequest until their parent dies, the comparison starts for agents of age 40. For them, we can compare the behavior of people whose parent died and did not leave them any asset 
(these children do not expect an inheritance anymore) with the behavior of people who still expect to receive something. The top line refers to the age-saving profile for the average agent in the case in which the agent does not expect to inherit. While the average expected bequest decreases over time, because of parental asset decumulation, the probability of the parent's death increases over time. These two forces balance out, decreasing the saving rate by similar amounts over the life cycle. The corresponding figure for Sweden is similar.

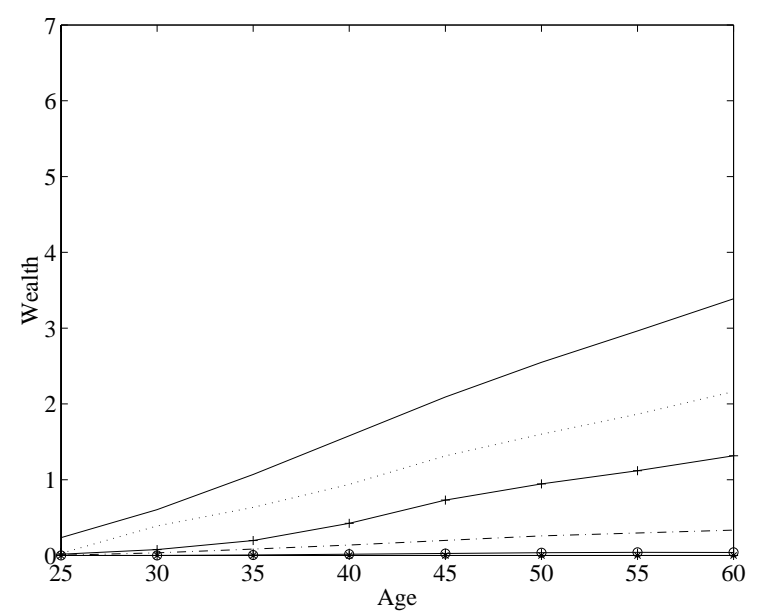

Figure 7: U.S. calibration. Wealth quantiles: $.1, .25, .5, .75, .85, .95$, conditional on not having inherited.

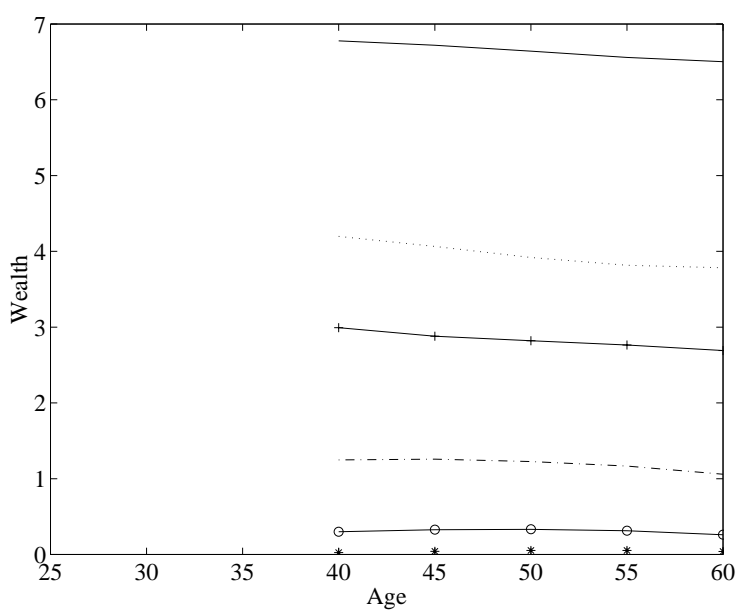

Figure 8: U.S. calibration. Wealth quantiles: $.1, .25, .5, .75, .85, .95$, conditional on having inherited.

Figures 7 and 8 show that in the simulations the wealth quantiles of the people who do receive a bequest are significantly higher than those who do not get a positive transfer of wealth from their parent.

\section{Discussion of the Assumptions}

In order to make the model manageable and solvable, I have made several simplifying assumptions. In this section I discuss the assumptions and their likely qualitative implications.

The assumption that children partially inherit their parents' productivity is meant to recover the fact that education and human capital are closely related to the family background of each person. Becker and Tomes (1979), (1986) study the parents' optimal investment decision in children's human capital in a setup in which human capital investment in children has decreasing returns, while the return on physical capital is fixed. In this setting parents 
begin investing in their children's human capital and then invest in physical capital when the return from human capital falls below the return on physical capital. In the presence of borrowing constraints, the poorest families only invest in their children, and they may not even be able to do so at the optimal level. The richest families not only invest in their children's human capital but also leave them physical capital. Poorer families will tend to have poorer children, thus generating persistence in the lower end of the wealth distribution. At the upper tail of the distribution, rich children might want to save less because they expect large bequests. However, they will also be richer (because of their dominant income process and the bigger transfers they receive from their parents); hence, they might want to save more. At the aggregate level, this will increase or decrease persistence at the upper end of the wealth distribution, depending on which effect dominates. Most likely, if the altruism toward their children is strong enough for the richer people, the desire to leave large estates to children will offset the reduction in saving because of the large bequests received. Which effect dominates thus depends on how wealth affects savings at high levels of wealth.

As discussed previously, I made restrictive assumptions on the information available to the children on their parent's wealth and income. These assumptions are made for computational reasons but are also likely to affect the results. In particular, I expect the model in the current version to display fatter tails at both ends of the wealth distribution, compared with a model in which the parent's assets and income are observable by the child. With perfect observability children of poor parents will save more, since they are aware that no bequest will be left to them. In contrast, children of richer parents will save less. If wealth of poor parents is easier to measure than wealth of rich parents, only the lower tail of the distribution of wealth would become thinner.

Another important assumption is that there are no inter vivos transfers. In the data these transfers often have a compensatory nature: parents tend to give when the children need money the most. This may happen when they go to college, start a new job, get married, buy a house, or get a sequence of bad shocks. This assumption is probably most relevant when children are 20 to 35 years of age and are starting off on their own. Allowing for inter vivos transfers would help reduce the number of people at zero wealth, especially among the young. 
I take fertility to be exogenous and independent of households' income. If poorer families tend to have more children, the amount of resources received by each child will be even lower, thus exacerbating wealth inequality. Knowles (1999) constructs a two-period, overlapping-generations model with fertility choice, human capital investment, and voluntary bequests, and he studies its implications on income and wealth inequality. The model is capable of matching the fact that higher-income households on average tend to have fewer children (with the possible exception, in the data, of the very richest families) and shows that fertility decisions can help in matching some features of income concentration. While this model does not generate the observed concentration of wealth in the upper tail of its distribution, it would be interesting to investigate the effect of differential fertility in a setup similar to the one used in this paper.

I assume labor earnings to be exogenous. This is a limitation for two reasons. First, labor supply might respond to the expectation of receiving a large bequest. Second, the U.S. data show a noticeable correlation between high wealth and entrepreneurial activity. Some households might accumulate huge fortunes because they face high implicit rates of returns, but they are not free to borrow as much as they wish to exploit these investment opportunities. Such a channel could be quantitatively important to fully account for the saving decisions of the very richest. Both of these mechanisms are left for future research.

I also assume that the probability of death is independent of wealth and ability. In the data the richer and more able people tend to live longer. Introducing heterogeneous mortality (or survival probabilities that depend on wealth or ability) into the model would not change the features of the saving behavior that are key in driving the results: poor people save primarily for self-insurance; richer people also save to leave bequests. Given reasonable assumptions on the life span, savings against life-span risk would remain a small fraction of total wealth for the richest people. Therefore, introducing differential mortality in this model (and, hence, a different timing of bequests) would not have a significant impact on wealth inequality, and on the upper tail of the distribution in particular.

The results I report in the paper do not make any adjustment on consumption and utility for the demographic changes the household is undergoing over time. Since Attanasio et al. (1999) found demographics to be important in their setup, I also experimented by 
using per-adult-equivalent scale consumption, depending on the children's age. (I used some estimates kindly provided by Guglielmo Weber.) When I introduced this modification, while at the same time adjusting the discount factor to obtain a comparable capital-output ratio, the results did not change in a quantitatively significant way. The intuition is related to the key features of saving behavior that I just described. Moreover, in this model, the hump-shaped behavior in consumption and wealth is generated by the presence of borrowing constraints (which generate the increasing part of the hump during youth) and age-dependent probability of death (which generates the decreasing part of the hump after retirement). 


\section{References}

Aaron, H. J., and A. H. Munnell (1992): "Reassessing the Role for Wealth Transfer Taxes," National Tax Journal, 45(2), 119-143.

Altonji, J. G., And E. Villanueva (2002): "The Effect of Parental Income on Wealth and Bequests," Mimeo, Northwestern University.

Attanasio, O. P., J. Banks, C. Meghir, and G. Weber (1999): "Humps and Bumps in Lifetime Consumption," Journal of Business and Economic Statistics, 17(1), 22-35.

Auerbach, A. J., and L. J. Kotlikoff (1995): Macroeconomics: An Integrated Approach. South-Western College, Cincinnati.

Becker, G. S., And N. Tomes (1979): "An Equilibrium Theory of the Distribution of Income and Intergenerational Mobility," Journal of Political Economy, 87(6), 1153-1189.

(1986): "Human Capital and the Rise and Fall of Families," Journal of Labor Economics, 4(3), 1-39.

Bell, F. C., A. H. Wade, and S. C. Goss (1992): Life Tables for the United States Social Security Area: 1900-2080. Social Security Administration, Office of the Actuary.

BJÖRkLund, A., And M. J̈̈ntTi (1997): "Intergenerational Income Mobility in Sweden Compared to the United States," American Economic Review, 87(5), 1009-1018.

Carroll, C. D. (1998): "Why Do the Rich Save So Much?" Working Paper 6549, National Bureau of Economic Research.

Castañeda, A., J. Díaz-Giménez, and J.-V. Ríos-Rull (1998): "Earnings and Wealth Inequality and Income Taxation: Quantifying the Trade-Offs of Switching to a Proportional Income Tax in the U.S.," Working Paper 9814, Federal Reserve Bank of Cleveland.

Cooley, T. F., and E. C. Prescott (1995): "Economic Growth and Business Cycles," in Frontiers of Business Cycle Research, ed. by T. F. Cooley. Princeton University Press, Princeton, NJ, 1-38.

Council of Economic Advisors (1998): Economic Report of the President. United States Government Printing Office, Washington.

DAvies, J. B. (1982): "The Relative Impact of Inheritance and Other Factors on Economic Inequality," Quarterly Journal of Economics, 9(3), 471-498.

Davies, J. B., And A. F. Shorrocks (2000): "The Distribution of Wealth," in Handbook of Income Distribution, ed. by A. B. Atkinson and F. Bourguignon. Handbooks in Economics, vol. 16. Amsterdam; New York and Oxford: Elsevier Science, North-Holland, 605-675.

De Nardi, M., L. Ren, and C. Wei (2000): "Income Inequality and Redistribution in Five Countries," Federal Reserve Bank of Chicago Economic Perspectives, 24(2), 2-20. 
Díaz-GimÉnez, J., V. Quadrini, and J.-V. RÍos-Rull (1997): "Dimensions of Inequality: Facts on the U.S. Distributions of Earnings, Income and Wealth," Federal Reserve Bank of Minneapolis Quarterly Review, 21(2), 3-21.

Dynan, K. E., J. Skinner, And S. P. Zeldes (1996): "Do the Rich Save More?" Manuscript, Board of Governors of the Federal Reserve System.

Gale, W. G., and J. K. Scholz (1994): "Intergenerational Transfers and the Accumulation of Wealth," Journal of Economic Perspectives, 8(4), 145-160.

Gokhale, J., L. J. Kotlikoff, J. Sefton, and M. Weale (1998): "Simulating the Transmission of Wealth Inequality via Bequests," Working Paper 9811, Federal Reserve Bank of Cleveland.

Gourinchas, P.-O., And J. A. Parker (2002): "Consumption over the Life Cycle," Econometrica, 70(1), 47-89.

Hansen, G. D. (1993): "The Cyclical and Secular Behaviour of Labour Input: Comparing Efficiency Units and Hours Worked," Journal of Applied Econometrics, 8(1), 71-80.

Hansson, B. (1989): "Construction of Swedish Capital Stocks," Economic Studies, Department of Economics, Uppsala University, 2.

Heer, B. (1999): "Wealth Distribution and Optimal Inheritance Taxation in Life-Cycle Economies with Intergenerational Transfers," Mimeo. University of Cologne, Germany.

Hubbard, R. G., J. Skinner, and S. P. Zeldes (1995): "Precautionary Saving and Social Insurance," Journal of Political Economy, 103(2), 360-399.

Huggett, M. (1996): "Wealth distribution in life-cycle economies," Journal of Monetary Economics, 38(3), 469-494.

Hurd, M. D. (1989): "Mortality Risk and Bequests," Econometrica, 57(4), 779-813.

Hurd, M. D., And J. P. Smith (1999): "Anticipated and Actual Bequests," Working Paper 7380, National Bureau of Economic Research.

Hurst, E., M. C. Luoh, and F. P. Stafford (1998): "The Wealth Dynamics of American Families, 1984-1994," Brookings Papers on Economic Activity, 1, 267-329.

Knowles, J. (1999): "Can Parental Decisions Explain U.S. Income Inequality?" Mimeo, Department of Economics, University of Pennsylvania.

Kotlikoff, L. J., K. A. Smetters, and J. Walliser (1999): "Privatizing Social Security in the United States: Comparing the Options," Review of Economic Dynamics, 2(3), $532-574$.

Kotlikoff, L. J., And L. H. Summers (1981): "The Role of Intergenerational Transfers in Aggregate Capital Accumulation," Journal of Political Economy, 89(4), 706-732. 
Krusell, P., And A. A. Smith, Jr. (1997): "Income and Wealth Heterogeneity, Portfolio Choice, and Equilibrium Asset Returns," Macroeconomic Dynamics, 1(2), 387-422.

LAitner, J. (1992): "Random Earnings Differences, Lifetime Liquidity Constraints, and Altruistic Intergenerational Transfers," Journal of Economic Theory, 58(2), 135-170.

(2001): "Secular Changes in Wealth Inequality and Inheritance," The Economic Journal, 111(474), 691-721.

Laitner, J., And H. Ohlsson (1997): "Equality of Opportunity and Inheritance: A comparison of Sweden and the U.S.," Mimeo.

Lillard, L. A., and L. A. Karoly (1997): "Income and Wealth Accumulation Over the Life-cycle," Manuscript, RAND Corporation.

Lillard, L. A., and R. J. Willis (1978): "Dynamic Aspects of Earning Mobility," Econometrica, 46(5), 985-1012.

Mulligan, C. B. (1997): Parental Priorities and Economic Inequality. Chicago: University of Chicago Press.

Nishiyama, S. (2000): "Measuring Time Preference and Parental Altruism," Mimeo, University of Pennsylvania.

Organisation for Economic Co-operation and Development (1999): OECD Economic Surveys, 1998-1999: Sweden. OECD, Paris and Washington, D.C.

Palsson, A.-M. (1993): "Household Risk Taking and Wealth: Does Risk Taking Matter?" in Research in Economic Inequality, vol. 4. Studies in the Distribution of Household Wealth. Daniel J. Slottje and Edward N. Wolff, eds. JAI Press.

PoterbA, J. (1998): "Estate and Gift Taxes and Incentives for Inter Vivos Giving in the United States," Working Paper 6842, National Bureau of Economic Research.

Quadrini, V. (2000): "Entrepreneurship, Saving and Social Mobility," Review of Economic Dynamics, 3(1), 1-40.

Statistics Sweden (1997): Statistical Yearbook of Sweden. Statistics Sweden, Web site: http://www.scb.se/indexeng.asp.

Tauchen, G., And R. Hussey (1991): "Quadrature-Based Methods for Obtaining Approximate Solutions to Nonlinear Asset Pricing Models," Econometrica, 59(2), 371-396.

WolfF, E. N. (1987): "Estimates of Household Wealth Inequality in the U.S., 1962-1983," Review of Income and Wealth, 33(3), 251-257.

Zimmerman, D. J. (1992): "Regression Toward Mediocrity in Economic Stature," American Economic Review, 82(3), 409-429. 


\section{Appendix A1. Transition Function}

From the policy rules, the bequest distribution, and the exogenous Markov process for productivity, we can derive a transition function $\tilde{M}(x ; \cdot)$. The transition function $\tilde{M}(x ; \cdot)$ is thus the probability distribution of $x^{\prime}$ (the state in the next period), conditional on $x$, for a person who behaves according to the policy rules $c(x)$ and $a(x) .{ }^{9}$ The measurable space over which $\tilde{M}$ is defined is $(\tilde{X}, \tilde{\mathcal{X}})$, with

$$
\begin{aligned}
& X \equiv\{1, \ldots, T\} \times \Re_{+} \times Y \times(Y \cup\{0\}), \\
& \mathcal{X} \equiv \mathcal{P}(\{1, \ldots, T\}) \times \mathcal{B}\left(\Re_{+}\right) \times \mathcal{B}(Y) \times \mathcal{B}(Y \cup\{0\}), \\
& \tilde{X} \equiv X \cup\{D\}, \\
& \tilde{\mathcal{X}} \equiv\{\tilde{\chi}: \tilde{\chi}=X \cup d, X \in \mathcal{X}, d \in\{\emptyset,\{D\}\}\},
\end{aligned}
$$

where $\mathcal{P}$ is the cardinal set of $\{1, \ldots, T\}$ and $D$ indicates that a person is dead.

To characterize $\tilde{M}$, it is enough to display it for the sets

$$
L(\bar{t}, \bar{a}, \bar{y}, \overline{y p}) \equiv\left\{\left(t^{\prime}, a^{\prime}, y^{\prime}, y p^{\prime}\right) \in X: t^{\prime} \leq \bar{t} \wedge a^{\prime} \leq \bar{a} \wedge y^{\prime} \leq \bar{y} \wedge y p^{\prime} \leq \overline{y p}\right\}
$$

\footnotetext{
${ }^{9}$ For simplicity of notation I keep the dependence of $\tilde{M}$ on $c, a, \mu_{b}$ implicit.
} 
On such sets $\tilde{M}$ is defined by $\tilde{M}(x, L(\bar{t}, \bar{a}, \bar{y}, \overline{y p}))=$

$$
\begin{cases}\alpha_{t} I_{t+1 \leq \bar{t}}\left[I_{a(x) \leq \bar{a}}\left(I_{y p=0}+I_{y p \leq \overline{y p}} \alpha_{t+5}\right)+\right. & \text { if } x \neq D \\ \left.\mu_{b}(x ;[0, \bar{a}-a(x)])\left(1-\alpha_{t+5}\right) I_{y p>0}\right] Q_{y}(y,[0, \bar{y}] \cap Y) & \\ & \text { if } x=D\end{cases}
$$

where $I$ is an indicator function, which equals one if the subscript property is true and zero otherwise.

To understand $\tilde{M}$, notice that $\alpha_{t}$ is the probability of surviving into the next period. Conditional on survival, a person currently of age $t$ will be of age $t+1$ next period; hence, the presence of $I_{t+1 \leq \bar{t}}$. If the person's parent is already dead, that is, $y p=0$, the person cannot receive bequests anymore, and his or her assets next period are $a(x)$ for sure. (As discussed above, this is always the relevant case for people 65 and older.) If, instead, the parent is still alive, that is, $y p>0$, the parent can survive into the next period with probability $\alpha_{t+5}$. In that case, tomorrow's assets for the person will be $a(x)$ and $y p^{\prime}=y p$. Alternatively, the parent may die, with probability $1-\alpha_{t+5}$. Under this scenario, the person inherits next period, $y p^{\prime}=0$, and the probability that next period's assets are no more than $\bar{a}$ is the probability of receiving a bequest between 0 and $\bar{a}-a(x)$. The person's evolution of productivity is described by $Q_{y}$. Note that the evolution of productivity, a person's survival, and the survival of the person's parent are independent of each other. Finally, death is an absorbing state.

Based on $\tilde{M}$, I can define an operator $R_{\tilde{M}}$ that maps probability distributions on $(\tilde{X}, \tilde{\mathcal{X}})$ :

$$
\left(R_{\tilde{M}} \tilde{m}\right)(\tilde{\chi}) \equiv \int \tilde{M}(x, \tilde{\chi}) \tilde{m}(d x), \forall \tilde{\chi} \in \tilde{\mathcal{X}}
$$

This operator describes the probability distribution of finding a person in state $x^{\prime}$ tomorrow, given 
the probability distribution of the state today. Such an operator has a unique fixed point, which is the probability distribution that attributes probability one to $\{D\}$ : everybody dies eventually. However, in the economy as a whole, I am not interested in keeping track of dead people, so I will define a modified operator on measures on $(X, \mathcal{X})$. Furthermore, I must take into account that new people enter the economy in each period. The transition function corresponding to the modified operator $R_{M}$ is thus

$$
M(x, L(\bar{t}, \bar{a}, \bar{y}, \overline{y p}))=\frac{\tilde{M}(x, L(\bar{t}, \bar{a}, \bar{y}, \overline{y p}))+n^{5} I_{t=5} Q_{y h}(y,[0, \bar{y}] \cap Y) I_{y \leq \overline{y p}}}{n} .
$$

The transition function $M$ differs from $\tilde{M}$ in two ways. First, it accounts for population growth; when population grows at rate $n$, a group that is $1 \%$ (say) of the population becomes $1 / n \%$ in the subsequent period. Second, it accounts for births, which explains the second term in the numerator. If a person is 40 years old $(t=5)$, that person's children (there are $n^{5}$ of them) will enter the economy next period. All of those children have age $t=1$ and zero assets. ${ }^{10}$ Their stochastic productivity is inherited from their 40-year-old parent, according to the transition function $Q_{y h} ; y$ (which is part of $x$ ) is their parent's productivity at 40 .

The operator $R_{M}$ is thus defined as

$$
\left(R_{M} m\right)(\chi) \equiv \int M(x, \chi) m(d x) \quad \forall \chi \in \mathcal{X}
$$

The operator $R_{M}$ maps measures on $(X, \mathcal{X})$ into measures on $(X, \mathcal{X})$, but it does not necessarily map probability measures into probability measures. Unless the population is at a demographic steady state, the total measure of people alive may grow at a rate faster or slower than $n$, which implies that $\left(R_{M} m\right)(x) \neq 1$ even if $m(x)=1$.

\footnotetext{
${ }^{10}$ Since $\bar{t} \geq 1$ and $\bar{a} \geq 0, \mathrm{I}$ do not need to include $I_{1 \leq \bar{t}}$ and $I_{0 \leq \bar{t}}$.
} 


\section{Appendix A2. Consistency of Bequest Distributions}

First define the marginal distribution of age and productivity in the population, which is a probability distribution on

$$
\begin{aligned}
& (\{1, \ldots, T\} \times Y, \mathcal{P}(\{1, \ldots, T\}) \times \mathcal{B}(Y)): \\
& m_{t, y}^{*}\left(\chi_{t, y}\right) \equiv m^{*}\left(\left\{x \in X:(t, y) \in \chi_{t, y}\right\}\right) \quad \forall \chi_{t, y} \in \mathcal{P}(\{1, \ldots, T\}) \times \mathcal{B}(Y) .
\end{aligned}
$$

Define $m^{*}(\cdot \mid t, y)$ as the conditional distribution of $x$ given $t$ and $y$. For any given $(t, y)$, $m^{*}(\cdot \mid t, y)$ is a probability distribution ${ }^{11}$ on $(X, \mathcal{X})$. For any set $\chi \in \mathcal{X}, m^{*}(\chi \mid t, y)$ is measurable with respect to $\mathcal{P}(\{1, \ldots, T\}) \times \mathcal{B}(Y)$ and is such that

$$
\int_{X_{t, y}} m^{*}(\chi \mid t, y) m_{t, y}^{*}(d t, d y)=m^{*}(\chi) \quad \forall \chi \in \mathcal{X} \quad \forall \chi_{t, y} \in \mathcal{P}(\{1, \ldots, T\}) \times \mathcal{B}(Y)
$$

The child observes the parent's productivity at age 40. The conditional distribution of the characteristics of the parent at age 40 , given a productivity level $y_{p}$, is ${ }^{12} m^{*}\left(\cdot \mid t=5, y=y_{p}\right)$. I want the characteristics of the parent at later ages, conditional on the parent's productivity as of age 40 being $y_{p}$ and conditional on not having died. Denote by $l\left(\cdot \mid t, y_{p}\right)$ these conditional distributions. They can be obtained recursively as follows: $l\left(\chi \mid 5, y_{p}\right)=m^{*}(\chi \mid 5, y p)$ and

$$
l\left(\chi \mid t+1, y_{p}\right) \equiv \frac{\int_{x} \tilde{M}(x, \chi) l\left(d x \mid t, y_{p}\right)}{\alpha_{t}} .
$$

The conditional distributions $l\left(\cdot \mid t, y_{p}\right)$ imply conditional distributions of assets $l_{a}\left(\cdot \mid t, y_{p}\right)$ on

\footnotetext{
${ }^{11}$ The conditional distribution $\left\{m^{*}(\chi \mid t, y)\right\}$ is uniquely defined up to sets of $m_{t, y}^{*}$-measure zero.

${ }^{12}$ I use $y_{p}$ to distinguish from both $y$ and $y p$ : $y_{p}$ plays the role of productivity for the parent (state variable $y$ ) and the parent's productivity for the child (state variable $y p$ ).
} 
$\left(\Re_{+}, \mathcal{B}\left(\Re_{+}\right)\right)$, which are given by

$$
l_{a}\left(\chi_{a} \mid t, y_{P}\right) \equiv l\left(\left\{x \in X: a \in \chi_{a}\right\} \mid t, y_{p}\right)
$$

Since the probability of death is independent of productivity and assets, the distribution of assets that are bequeathed by dying parents is the same as the distribution of assets of surviving parents. I thus have

(A1)

$$
\begin{aligned}
& \mu_{b}\left((t, a, y, y p) ; \chi_{a}\right)= \\
& l\left(a \in \Re_{+}: n^{5}\left(\prod_{s=1}^{t-1} \alpha_{s}\right)^{-1}\left[a I_{a \leq e x_{b}}+\left(e x_{b}+\frac{a-e x_{b}}{\left(1-\tau_{b}\right)}\right) I_{a>e x_{b}}\right] \in \chi_{a} \mid t+5, y p\right) \\
& \forall \chi_{a} \in \mathcal{B}\left(\Re_{+}\right) \quad \forall a \in \Re_{+} \quad \forall y, y p \in Y, \quad t=1, \ldots, T-5 .
\end{aligned}
$$

In equation (A1), I take into account the assumptions made before about the structure of bequest taxation and the assumption that the bequest is distributed evenly among surviving children.

I now need to define $\mu_{b}$ when $t=T-4$, which is the last age at which a person can inherit. Since there are no survivors at age $T+1$, I cannot use the survivor's assets to compute the assets that are bequeathed. Instead, I use the policy function $a(x)$ to define

$$
l_{a}\left(\chi_{a} \mid T+1, y p\right) \equiv \int_{X} I_{a(x) \in \chi_{a}} l(d x \mid T, y p) \quad \forall \chi_{a} \in \mathcal{B}\left(\Re_{+}\right) .
$$

With this definition, equation (A1) can be extended to $t=T-4$ as well. Equation (A1) is thus the formal requirement of consistency on $\mu_{b}$. 


\section{Appendix A3. More on the Calibration}

Survival probabilities: In the calibration of the U.S. economy, I use the mortality probabilities of people born in 1965 (which are for the most part projected, since these people are still young) provided by Bell, Wade, and Goss (1992). The Statistical Yearbook of Sweden (1997) provides the mortality probabilities for people at various ages in 1991-95. Since life expectancy is increasing, the Swedish data underestimate the life expectancy at the various ages with respect to the one faced by people born in 1965 in Sweden. To correct for this problem, I use the U.S. data to compute the relative increase in life expectancy for the relevant period. I then correct the Swedish data assuming that the increase in life expectancy is the same in the two countries. However, as a check, I also us the U.S. conditional probabilities in the simulation of the Swedish economy. It turns out that this has a negligible impact on the results even if the life expectancy of Swedish people is about three years longer than that of U.S. people.

Age-efficiency profile vector $\epsilon_{t}$ : I assume it to be the same in both countries. Its source is Hansen (1993).

The rates of population growth, $n$, are set to the respective average population growth from 1950 to 1997 for each country (Economic Report of the President (1998), and OECD Economic Surveys, 1998-1999: Sweden (1999)).

The ratio of $g$ (total government expenditure and gross investment, excluding transfers - which includes federal, state and local for the U.S.) to GDP comes from the Economic Report of the President (1998) and OECD Economic Surveys, 1998-1999: Sweden (1999) for 1996.

The capital income tax $\tau_{a}$ (computed by Kotlikoff, Smetters, and Walliser (1999) for the United States) is equal to a flat tax rate of $30 \%$ in Sweden (Statistics Sweden, Web site: http://www.scb.se/indexeng.asp).

Estimates for the log income process using PSID income data aggregated over five years are very 
kindly provided by Joe Altonji and Ernesto Villanueva. The regressions were run as follows.

\begin{tabular}{llcccc}
\hline & & \multicolumn{5}{c}{ Specification } \\
Left-hand side variable & & 1 & 2 & 3 & 4 \\
\hline Husband's earnings & persistence & 0.92 & 0.91 & .87 & 0.86 \\
& variance & 0.41 & 0.41 & 0.31 & 0.30 \\
& & & & & \\
Husband's earnings & persistence & 0.90 & 0.89 & 0.84 & 0.81 \\
plus wife's earnings & variance & 0.38 & 0.36 & 0.29 & 0.27 \\
& & & & & \\
Husband's earnings & persistence & 0.94 & 0.94 & 0.88 & 0.87 \\
plus unempl. insurance & variance & 0.41 & 0.38 & 0.32 & 0.31 \\
plus workmen's compensation & & & & & \\
& & & & & \\
$\begin{array}{l}\text { Husband's earnings } \\
\text { plus wife's earnings } \\
\text { plus unempl. insurance } \\
\text { plus workmen's compensation }\end{array}$ & persistence & 0.92 & 0.90 & 0.85 & 0.80 \\
\hline
\end{tabular}

Table 7: Log earnings persistence and variance.

Specification 1: Regressors are year dummies (take value 1 if the year is the first of a period of five) and a fourth order polynomial in age, in differences from 40 .

Specification 2: Same regressors as in (1), plus an extra intercept for nonwhite.

Specification 3: Same regressors as in (2), plus dummies for less than 5 years of schooling, more than 5 and less than 8 , more than 8 and less than 11, college dropout, college, and more than college. Specification 4: Same regressors as in (3), plus intercept for not married, whether there are children in the household, and the number of children.

The estimates for persistence and variance in the upper half of the table are based on the sample of male heads of household in the PSID for the period 1968-97. The PSID was divided in equally spaced 5-year periods, and income was aggregated within those cells. Only complete income spells of five years were used staring in 1968, 1973, 1978, 1983, and 1993.

The estimates in the lower half of the table are based on a sample of males in the PSID 
for the period 1978-97, given that questions about the exact amount of unemployment insurance and workmen's compensation are only available from 1977 on. Income from both unemployment insurance and workmen's compensation are asked of husband and wife.

In all specifications, observations with earnings below five times 900 dollars (from 1993) are dropped. The variance is taken from the pooled cross-section and time series variation of the prediction errors in the corresponding regression.

In my calibration for the United States, I choose the persistence and variance parameters from the regression that includes log earnings of the husband, earnings of the wife, and transfers and that pertain to the third specification, the one that accounts for age, race, and some education effects. This is a middle-of-the-range estimate among the relevant ones. It should be noted, however, that the range of the estimated parameters from the various regressions is rather tight.

I convert both the productivity and the productivity inheritance processes to four-state discrete Markov chains according to Tauchen and Hussey (1991). Since I want the possible realizations for the initial inherited productivity level to be the same as the possible realizations for productivity during the lifetime, I choose the quadrature points jointly for the two processes. The resulting gridpoints for the productivity process $y$ for the United States and for Sweden are, respectively: $[0.2594, \quad 0.6513, \quad 1.5355, \quad 3.8547]$ and $[0.3941, \quad 0.7438, \quad 1.3444, \quad 2.5373]$. Given the assumptions on the parameters of the processes, the transition matrices $Q_{y}$ and $Q_{y h}$ for the United States and Sweden are the same, and are given, respectively, by

$$
\left[\begin{array}{cccc}
0.7132 & 0.2764 & 0.0104 & 0.0000 \\
0.1467 & 0.6268 & 0.2210 & 0.0055 \\
0.0055 & 0.2210 & 0.6268 & 0.1467 \\
0.0000 & 0.0104 & 0.2764 & 0.7132
\end{array}\right]
$$




$\left[\begin{array}{cccc}0.5257 & 0.4228 & 0.0509 & 0.0007 \\ 0.1461 & 0.5538 & 0.2825 & 0.0176 \\ 0.0176 & 0.2825 & 0.5538 & 0.1461 \\ 0.0007 & 0.0509 & 0.4228 & 0.5257\end{array}\right]$.

Table 8 reports data on earnings distributions for the United States and Sweden, respectively, and compares them with the earnings distributions used in the model. The tables are computed using data for households whose head is 25 to 60 years of age. For each country the first row refers to gross earnings (which include wages, salaries, and self-employment income); the second row adds social insurance transfers to gross earnings; while the third row reports the earnings distribution implied by the model.

\begin{tabular}{|c|c|c|c|c|c|c|}
\hline \multirow[b]{2}{*}{$\begin{array}{l}\text { Gini } \\
\text { coeff. }\end{array}$} & \multicolumn{6}{|c|}{ Percentage earnings in the top } \\
\hline & $5 \%$ & $10 \%$ & $20 \%$ & $40 \%$ & $60 \%$ & $80 \%$ \\
\hline \multicolumn{7}{|c|}{ U.S. earnings data } \\
\hline .46 & 19 & 30 & 48 & 72 & 89 & 98 \\
\hline \multicolumn{7}{|c|}{ U.S. earnings + social insurance transfers } \\
\hline .44 & 19 & 30 & 47 & 71 & 88 & 97 \\
\hline \multicolumn{7}{|c|}{ U.S. simulated earnings } \\
\hline .44 & 15 & 30 & 50 & 73 & 87 & 96 \\
\hline \multicolumn{7}{|c|}{ Swedish earnings data } \\
\hline .40 & 15 & 25 & 42 & 68 & 86 & 98 \\
\hline \multicolumn{7}{|c|}{ Swedish earnings + social insurance transfer } \\
\hline .33 & 13 & 22 & 37 & 62 & 80 & 94 \\
\hline \multicolumn{7}{|c|}{ Swedish simulated earnings } \\
\hline .33 & 12 & 24 & 40 & 65 & 81 & 93 \\
\hline
\end{tabular}

Table 8: Earnings.

Estate taxes: According to U.S. law, each individual can make an unlimited number of tax-free gifts of $\$ 10,000$ or less per year, per recipient; therefore, a married couple can transfer $\$ 20,000$ per year to each child, or other beneficiary. For larger gifts and estates, there is a unified credit, that is, 
a credit received by the estate of each deceased, against lifetime estate and gift taxes. For the period between 1987 and 1997, each taxpayer received a tax credit that eliminated estate tax liabilities on estates valued at less than $\$ 600,000$. The marginal tax rate applicable to estates and lifetime gifts above that threshold is progressive, starting from 37\% (Poterba (1998)). However, the revenue from estate taxes is very low (on the order of .2\% of GDP in 1985-97) because there are many effective ways to avoid such taxes. (See, e.g., Aaron and Munnell (1992).) Moreover, only about 1.5\% of decedents pay estate taxes. Therefore, in the model I set $e x_{b}$ to be 40 times the median income and $\tau_{b}$ to be $10 \%$ to match the observed ratio of estate tax revenues to GDP and the proportion of estates that pay estate taxes. I discuss the sensitivity of the model to the choice of these two parameters when describing the results. For Sweden, I take the effective tax rate to be higher than that for the United States, 15\%, and the exemption level to be lower, 10 years of average labor earnings. In Sweden taxes are paid on inheritances, rather than on estates, and the revenue from inheritance and gift taxes is approximately .1\% of GDP. The statutory tax rate for children's inheritance is higher than in the United States (for the first bracket it is about 50\%) and the exemption level is much lower (on the order of $\$ 5,000$ ), but there are legal ways, for example, bequeathing an apartment or a large firm, of obtaining a much larger exemption level. It is therefore more difficult than in the United States to define the statutory exemption level. The combined choice of $\tau_{b}$ and $e x_{b}$ matches the revenues from bequests and gift taxes. 